\title{
Original_Article
}

\section{Neuropathic changes in young type 2 diabetes mellitus related to high serum t-PA}

\author{
Bhowmik NB', Hassan $Z^{2}$, Parvin $S^{3}$, Hasan $Z R^{4}$, Ali $L^{5}$
}

\begin{abstract}
:
Background and Aims: A substantial number of diabetic patients, diagnosed at relatively younger age, who don't fit to typical type 2 and type 1 class of diabetes. These patients usually present with very high level of glycemia. The uniqueness of this group of patient provide the opportunity to explore the pathophysiology of nerve functional status at an early stage of diabetes. The present study was aimed to determine markers of endothelial dysfunction and evaluate nerve functional status of a group of newly diagnosed clinically uncomplicated young diabetic patients. Material and Methods: A total number of 32 (male-13 and female-19) newly diagnosed young (diabetes diagnosed under 30 yrs) were consecutively recruited from BIRDEM Out-patient department and 30 age-, BMI-matched healthy subjects with no family history of diabetes up to second generation served as controls. Serum fructosamine was measured by reduction test with NBT method. Serum C-peptide, endothelin-1 and tissue plasminogen activator (t-PA) by ELISA and von Willibrand factor (vWF) by Radial Immunodiffusion (RID) methods. Urinary albumin measured by immunoturbidimetry method. Nerve functional status was evaluated by nerve conduction velocities (NCV), distal latencies (DL), compound muscle action potential (CAMP), F wave latencies (FWL), nerve action potential (SNAP) for motor and sensory nerve as appropriate following the standard protocol. Results: Severe hyperglycemia in the diabetic group was reflected in their mean (SD) fasting C-peptide and fructosamine level. Altered endothelial dysfunction, as evidenced by significantly high tissue plasminogen activator $(\mathrm{t}-\mathrm{PA})(\mathrm{p}<0.001)$ in the diabetic group. Albumin creatinine ratio (ACR) was almost similar in the two groups. Ulnar distal latency was similar in both the groups. But its CAMP and NCV were significantly lower in the diabetic group $(\mathrm{p}<0.02-0.001)$. Ulnar $\mathrm{F}$ wave latency were significantly higher $(\mathrm{p}=0.016)$ in the diabetic group. Ulnar sensory conduction parameters did not show any difference between two groups. Peroneal motor and sural sensory functional status of the diabetic subjects showed similar trend like that of ulnar motor and sensory status. Peroneal nerve motor NCV was significantly negtively correlated with fasting glucose $[\mathrm{r}=-$ 0.456, $\mathrm{p}=0.001]$. Peroneal motor distal latency was significantly correlated with fasting fractosamine [r=0.439, $\mathrm{p}=0.012]$. Fasting fructosamine showed significant negative correlation with motor peroneal NCV [ $\mathrm{r}=-0.572, \mathrm{p}=0.001]$, motor ulnar NCV [ $\mathrm{r}=-0.468, \mathrm{p}=0.007]$, both ulnar and sural sensory NAP ( $\mathrm{p}=0.02$ for both]. On the basis of $\mathrm{F}$ wave latency $53 \%$ of diabetic subjects had diabetic neuropathy and markedly higher t-PA compared to nonneuropathy groups $(\mathrm{p}=0.001)$. Conclusions: The data suggest that (i) Young type 2 diabetic subjects had endothelial dysfunction at the time of diagnosis even in the presence of normoalbuminuria state; (ii) Motor nerve conduction parameters are affected more than the sensory component; (iii) F wave latencies are more frequently and early to be involved in these subjects and linked to high serum t-PA.
\end{abstract}

Key words: Neuropathy, young type 2 diabetes, t-PA, hyperglycemia,

DOI: http://dx.doi.org/10.3329/bjms.v13i2.18302 Bangladesh Journal of Medical Science Vol.13(2) 2014 p.190-197

1. NB Bhowmik, Dept of Neurology, BIRDEM General Hospital, 122 Kazi Nazrul Islam Avenue, Dhaka-1000

2. Z Hassan, Dept of Physiology \& Molecular Biology, Bangladesh University of Health Sciences (BUHS), 125/1 Darus Salam Road, Mirpur, Dhaka-1216

3. S Parvin, Dept of Pharmacology, Shahabuddin Medical College, Plot-12, Road-113/A, Gulshan Model Town, Gulshan-2, Dhak-1212

4. ZR Hasan, Department of Neurology, Bangabhandhu Sheikh Mujib Medical University (BSMMU), Shahabag, Dhaka-100

5. L Ali, Dept of Biochemistry \& Cell Biology, Bangladesh University of Health Sciences (BUHS), 125/1 Darus Salam Road, Mirpur, Dhaka-1216

Corresponds to: Dr Nirmalendu Bikash Bhowmik, Associate Professor, Department of Neurology, Room \# 1422, BIRDEM General Hospital, 122 Kazi Nazrul Islam Avenue, Dhaka-1000

E-mail: bhowmiknbb24@gmail.com 


\section{Introduction:}

Neuropathy is the commonest complication of diabetes mellitus and is, by far the greatest source of morbidity and mortality of the diabetics ${ }^{1}$. Overall incidence of diabetic neuropathy reported to be 2\% in the United Kingdom Prospective Diabetes Study (UKPDS) and the Diabetes Control and Complications Trial (DCCT) 2,3 . It was shown that around $7 \%$ of patients had peripheral neuropathy at diagnosis of diabetes and $20 \%$ and $30 \%$ of the hospitalized and community diabetic patients have neuropathy 4,5 .

The underlying pathophysiology of diabetic peripheral neuropathy is not well understood. However, chronic hyperglycemia has been shown as key initiator of neurovascular damage 6,7,8. Endothelial dysfunction shown to be associated with raised blood level of tissue plasminogen activator (t-PA), endothelin 1 (ET1) and von Willebrand Factor $(\mathrm{vWF})^{9-13}$. Role of hyperglycemia in the pathogenesis of microangipathy ultimately leading to neuropathy was substantiated by findings that endothelial cells exposed to high glucose concentration over expresses $\mathrm{t}-\mathrm{PA}^{14}$. We have also reported raised blood ET1 in type 2 diabetes mellitus linked to hyperglycemia $^{15}$. vWF was shown to be associated with neuropathy in diabetic cases which, however, showed correlation with duration of diabetes ${ }^{12}$.

Characteristics features of peripheral neuropathy are abnormalities in nerve conduction studies. Abnormalities in nerve conductions often reflected as the early features of neuropathy ${ }^{16}$. Nerve conduction studies, remained to be the most objective noninvasive measures of nerve function which represent sensitive and specific tools to detect diabetic neuropathy in clinical and epidemiological studies $^{17,18}$. Clinical measures of neuronal dysfunction are often dissociated from presence of abnormalities of nerve conduction studies ${ }^{19}$. However, $F$ wave latency rather than conduction parameters appeared to be more sensitive ${ }^{19}$. Up to $68 \%$ of nerves having normal conduction velocities has been found to have abnormal $\mathrm{F}$ wave latencies ${ }^{20}$.

Diabetes mellitus, mainly of type 2 variety is commonly prevalent in Bangladesh like other countries of the world ${ }^{21}$. Although typical type 1 diabetes is relatively uncommon in Bangladesh but a substantial proportion of diabetic patients are younger, usually below 30 years of age who does not either of the typical type 1 and type 2 diabetes mellitus. However, according latest WHO classification of diabetes this group of patients is placed in the second variety 22 . Characteristics features of these patients are lean to moderately overweight, marked hyperglycemia, hypoinsulinemia but lack of ketosis proneness. Moreover they are usually normolipidemic and normotensive ${ }^{23}$. However, microvascular complications more commonly found in these patients ${ }^{24}$. Taking advantage of the uniqueness of these groups of patients the present study was undertaken to measure the nerve conduction parameters and markers of endothelial dysfunction to explore the pathological basis of its neuropathy.

\section{Material and Methods}

\section{Subjects}

A total number of 32 newly diagnosed young diabetic subjects, age below 30 yrs, consecutively attending the Out-patient department of BIRDEM, the central institute of Bangladesh Diabetic Samiti (BADAS), were recruited. Older patients, age more than 30 years and those had acute and chronic diabetic complications and other illness as evidenced by laboratory investigations (total blood count, ESR, serum SGPT, urea and creatinine) and young women with pregnancy were excluded.

Age and BMI matched 30 healthy subjects with no family history of diabetes up to second generation served as controls. The nature and purpose of the study was stated to each of the participants and written consent obtained. Diabetes was diagnosed according WHO criteria ${ }^{22}$.

\section{Methods}

\section{Collection of blood}

Overnight fasting blood sample $(10 \mathrm{ml})$ was collected from antecubital vein following all aseptic precaution. Blood sample was allowed to clot for 30 min and centrifuged at $3000 \mathrm{rpm}$ for $10 \mathrm{mins}$. Separated serum was aliquoted and preserved $-40^{\circ} \mathrm{C}$ for further biochemical analyses.

\section{Biochemical methods}

Glucose was measured by glucose-oxidase; serum fructosamine by enzymatic colorimetric method; Cpeptide, endotheline 1, tissue plasminogen activator (t-PA) by Enzyme linked immunosorbant assay (ELISA) method and von Willebrand factor (vWF) 
by Radial Immunodiffusion (RID).

Urinary albumin was determined by immunoturbiditry method using first voided morning urine sample.

\section{Nerve conduction study}

Peripheral nerve motor nerve conduction velocities (NCV), distal latencies (DL), compound muscle action potentials (CAMP), and $\mathrm{F}$ wave latencies (FWL) were determined following standard protocol. For upper limb, unilateral studies of motor and sensory conduction of ulnar nerve including $F$ wave latencies were measured. For lower limbs unilateral study of peroneal nerve for motor conduction including $\mathrm{F}$ wave latency were measured. Unilateral study of sural nerve for sensory conduction was done for sensory conduction.

Nerve conduction velocity was measured by a standard EMG machine in a room with a temperature of $37^{\circ} \mathrm{C}$. Nerve conduction parameters were included according to the protocol recommended by San Antinio Conference on diabetic neuropathy 25 .

\section{Statistical Methods}

Data were expressed as mean \pm SD and median (range) unless otherwise stated. The comparison between the groups was made by unpaired Student's-' $t$ ' and/ or Mann Whitney Rank sum test, as appropriate, using Statistical Package for Social Science (SPSS) for Windows Version 10. P value $<0.05$ was considered as level of significant.

\section{Results:}

Baseline clinico-biochemical data were shown in table 1. Age and BMI of the two groups were matched. Very high fasting glucose (mmol/l, mean \pm SD) level in the diabetic group reflected in their significantly lower fasting C-peptide (nmol/l, mean $\pm S D, p<0.0001)$ and higher serum fructosamine $(\mathrm{mmol} / \mathrm{l},(\mathrm{p}<0.001)$ levels compared to the controls. Renal functional status of the diabetic subjects was normal as evidenced by albumin creatine ratio ( $\mu \mathrm{g}$ albumin/g creatinine) (Table 1 ).

Endothelial cell dysfunction markers were shown in table 2. Diabetic group had significantly higher t-PA level compared to the controls $(\mathrm{p}=0.001)$.

Motor nerve conduction of ulnar nerve was shown in table 3. Ulnar distal latency (msec, mean \pm SD) was almost similar in the two groups. In diabetic subjects ulnar compound muscle action potential (mm, mean $\pm \mathrm{SD}$ ) and nerve conduction velocity $(\mathrm{m} / \mathrm{sec}$, mean \pm SD were significantly lower compared to the Controls ( $p=0.017$ and 0.0001 respectively). $F$ wave latency (mse, mean $\pm \mathrm{SD}$ ) was significantly higher in the diabetes group compared to the control counterpart $\mathrm{p}=0.016$ ) (Table 3). Ulnar sensory nerve conduction study in the diabetic group did not show significant difference compared to the controls (Table 4).

Peroneal motor nerve conduction was shown in table 5. Peroneal distal latency (ms, mean \pm SD) in the two groups was similar. Peroneal CMAP (mv, mean \pm SD) and NCV (m/sec, mean \pm SD) were significantly lower in the DM subjects ( $\mathrm{p}=0.001)$ compared to the Controls and $\mathrm{F}$ wave latency (ms, mean $\pm \mathrm{SD}$ ) significantly higher $(\mathrm{p}=0.001)$ compared to the counterpart (Table 5).

Sural distal latency (ms, mean \pm SD) and sensory SNAP (mv) in the diabetic group did not statistical difference compared to the controls. But Sural NCV $(\mathrm{m} / \mathrm{s}$, mean $\pm \mathrm{SD})$ was significantly lower in the diabetic $(\mathrm{p}=0.019)$ group compared to the counterpart (Table 6).

\section{Correlation analysis}

Motor peroneal nerve conduction velocity was found to be negtively correlated with fasting glucose $[r=-0.456, p=0.001]$. Motor peroneal distal latency showed significant positive correlation with fasting fractosamine $[r=0.439, p=0.012]$. Fasting fructosamine also showed significant negative correlation with motor Peroneal NCV $[\mathrm{r}=-0.572, \mathrm{p}=0.001]$, motor Ulnar NCV [ $\mathrm{r}=-0.468, \mathrm{p}=0.007]$, both Ulnar and Sural SNAP ( $\mathrm{p}=0.02$ for both] (Table 7).

Mean+2SD of $F$ wave latency of peroneal nerve of the controls $(47.4 \mathrm{mv} / \mathrm{sec})$ was taken as upper normal limit and diabetic subjects were sub-grouped as diabetic nonneuropthy (DNN) and neuropathy (DN) groups. Out of 32 diabetic subjects 17 (53\%) fell in the DN group. The DN subgroup had significantly higher t-PA serum t-PA compared to the DNN subgroup $(p<0.01)$. Serum t-PA value between DNN and the Controls did not show significant difference (Table 8).

\section{Discussion:}

Detection and sometimes grading of diabetic neuropathy is of interest for researchers and clinicians not only for diagnosis and management purpose but also for understanding the disease process. In the present study nerve conduction studies were performed among the group of newly diagnosed young 
diabetic patients. These subjects presented with severe degree of hyperglycemia, however, had no sign of ketosis. They had also markedly compromised basal insulin secretion as judged by low mean C-peptide $(0.199 \mathrm{nmol} / \mathrm{l})$. The study subjects did not have microvascular complication as revealed by almost similar urinary albumin creatine ratio with that of the controls. This scenario provided unique opportunity to perform nerve conduction studies and study its pattern in these subjects and explore the relationship with markers of vasculopathies.

Sensory nerve conduction parameters were not all affected in the upper limb as judged by almost similar value of ulnar distal latency, sensory nerve action potential and nerve conduction velocity. However, sural sensory nerve conduction velocity was significantly slower in the diabetic group where as its distal latency and sensory nerve action potential was almost similar to that of the controls.

Motor nerve conduction abnormalities were pronounced of the diabetic subjects both in ulnar and peroneal nerve. This is consistent with previous observation in a group of newly diagnosed subjects 26 . It is interesting to observe that both ulnar and peroneal nerve distal latency in the diabetic group did not show significant difference compared to the controls. However, peroneal motor distal latency showed significant negative correlation with serum fructosamie level promting suggestion that though the mean value of the group did not show statistical difference from the controls but still hyperglycemia plausibly impede their nerve functional status. Negative correlation between fasting glucose level and peroneal motor nerve conduction velocity and fructosamine and ulnar, peroneal and sural nerve conduction study parameters are in line with the proposition that recent hyperglycemia affects the conduction abnormalities ${ }^{27}$. Correlation with nerve parameters implies that there is demylination as well as axonal degeneration in young diabetic patients.

Cut-off value for nerve conduction variables was determined taking mean $\pm 2 \mathrm{SD}$ values of the controls except compound muscle action potential ${ }^{28}$. All subjects in the control group all and 28 (87.5\%) young type 2 diabetic subjects also had normal peroneal nerve conduction velocity. But peroneal $\mathrm{F}$ wave latency was prolonged in 17 (53.12\%) study subjects and none in the control group. Ulnar motor nerve conduction velocity was slow in 6 (18.75\%) where as its $\mathrm{F}$ wave latency was prolonged in 16 (50\%) diabetic subjects. Only 5 (15.62\%) diabetic subjects had prolonged sural sensory conduction velocity. This pattern of abnormalities in the nerve conduction studies is supported by the previous studies 16,20 . Cut-off value for compound muscle action potential (CAMP) and sensory nerve action potential (SNAP) was also calculated ${ }^{28}$. In diabetic group 13 (40.62\%) and 4 (12.5\%) had CAMP of low amplitude for peroneal nerve ulnar nerve respectively. Low amplitude for ulnar and sural SNAP was in 2 (6.25\%) and 7 (21.8\%) respectively in diabetic group.

Since it is argued that endothelial microangiopathy is related in human diabetic neuropathy 29,30 we measured t-PA, ET-1 and vWF in newly diagnosed young type 2 diabetic subjects. Of the three markers of endothelial dysfunction, estimated in this study, tPA and ET-1 were significantly higher in the diabetic subjects and vWF was, however, almost similar to that of the control group. The high t-PA level is supported by different other studies which substantiate the plausible fact that hyperglycemia might be inducing endothelial injury 9,10,31. Cut-off value of peroneal F wave latency was applied and 17 (53.1\%) found to be have diabetic neuropathy who had significantly high tPA level than the diabetic non-neuropathy and control groups (Table 8). ET-1 and vWF were almost similar in the eventual three groups. tPA showed negative correlation with serum fructosamine but did not show any correlation with peroneal F wave latency. Hence, a causal relationship between t-PA with diabetic neuropathy might not be made, however, further studies are required to clarify the issue. These findings suggest that t-PA might be an early marker of endothelial dysfunction and has a role in diabetic neuropathy.

Endothelin-1 level is elevated in diabetic subjects. It has been claimed previously that hyperglycemia induces high blood level of ET-1 possibly due to the fact of endothelial damage ${ }^{11}$. The finding of the present study also supports the claim and in a recent article high blood glucose was shown to be main stimulant of blood elevated of ET- ${ }^{15}$. However, no correlation for Endothelin-1 with fasting glucose and fructosamine level was observed. The pathophysiological role of Endothelin-1 and vWF in neuropathy needs to be evaluated further. 
vWF was implicated in the pathogenesis of diabetic neuropathy. In the present study serum vWF level is almost similar which is in contrast with previous findings 12,13 . It was also reported that serum vWF is associated with duration of diabetes not acute change of blood glucose 32 , 33. It may be recalled that the young diabetic patients were newly diagnosed and it is understood that these group of diabetic patient usually have sudden onset of disease which may clarify the lack of rise in vWF in this case. No correlation of vWF and Endothelin-1 was found with fasting glucose and serum fructosamine. Such a finding was supported by previous studies 11,30 . The data suggests that young diabetic patients at diagnosis have neuropathy particularly of motor nerve conduction abnormality of both upper and lower limb which is possibly due to acute hyperglycemia. Peroneal F wave latency study appeared to be a sensitive marker and may be done as routine electrophysiological investigation of the young type 2 diabetic patients to detect presence of nerve function abnormality at diagnosis. Endothelial dysfunction, in particular high serm t-PA is also evident in these patients which may not be directly related to the pathogenesis of neuropathy. Further studies, however, needed to conclusively understand the basis pathological basis of neuropathy in these young diabetic patients.

\section{Acknowledgement}

The authors gratefully acknowledge the young diabetic patients and control subjects to volunteer for the study. Bangladesh Diabetic Association and International Program for the Chemical Sciences (IPICS) are also acknowledged for the financial and logistic support to conduct the study.

Table 1: Baseline clinical and glycemic status and renal functional status of the study subjects

\begin{tabular}{l|c|c|c}
\hline Variables & DM Subjects $(\mathrm{n}=32)$ & Control subjects $(\mathrm{n}=30)$ & $\mathrm{p}$ value \\
\hline Male $($ Female $)$ & $13(19)$ & $23(7)$ & NS \\
Age $($ Yrs $)$ & $24.1 \pm 3.9$ & $23.4 \pm 2.7$ & 0.44 \\
BMI $\left(\mathrm{Kg} / \mathrm{m}^{2}\right)$ & $19.1 \pm 3.5$ & $19.4 \pm 2.2$ & 0.76 \\
F glucose $(\mathrm{mmol} / \mathrm{l})$ & $18.65 \pm 6.73$ & $4.80 \pm 0.55$ & \\
F C-pep $(\mathrm{nmol} / \mathrm{l})$ & $0.199 \pm 0.167$ & $0.393 \pm 0.236$ & 0.0001 \\
S Fruct $(\mu \mathrm{mol} / \mathrm{l})$ & $644 \pm 226$ & $222 \pm 36$ & 0.001 \\
ACR $(\mathrm{mg} / \mathrm{g})$ & $0.84 \pm 1.09$ & $1.74 \pm 3.61$ & 0.20 \\
\hline
\end{tabular}

Results were expressed as mean $\pm \mathrm{SD}$.

Student's Unpaired ' $t$ '-test was performed to calculated statistical difference between groups. $\mathrm{P}$ value $<0.05$ was taken as level of significance.
Group 1, Young diabetic subjects; Group 2, Healthy controls

F glucose, fasting glucose; F C-pep, Fasting C-peptide, S Fruct, Serum fructosamine ACR, Albumin creatinine ratio

Table 2: Serum levels of markers of endothelialdysfunction in the study subject

\begin{tabular}{l|c|c|c}
\hline Variables & DM Subjects $(\mathrm{n}=32)$ & Control Subjects $(\mathrm{n}=30)$ & $\mathrm{p}$ value \\
\hline ET-1 $(\mathrm{pgm} / \mathrm{ml})$ & $1.62 \pm 0.96$ & $1.24 \pm 0.44$ & 0.049 \\
t-PA $(\mathrm{ng} / \mathrm{ml})$ & $14.31 \pm 10.81$ & $7.04 \pm 2.48$ & 0.001 \\
vWF $(\mathrm{IU} / \mathrm{ml})$ & $1.80 \pm 0.49$ & $1.76 \pm 0.72$ & 0.79 \\
\hline
\end{tabular}

Results were expressed as Mean $( \pm \mathrm{SD})$.

Student's Unpaired ' $t$ '-test was performed to calculated statistical difference between groups. P value $<0.05$ was taken as level of significance.

t-PA, tissue Plasminogen Activator; ET-1, Endothelin-1; vWF, von Willibrand Factor.

Table 3: Motor nerve conduction parameters of ulnar nerve

\begin{tabular}{l|c|c|c}
\hline Variables & DM Subjects $(\mathrm{n}=32)$ & Control Subjects $(\mathrm{n}=30)$ & $\mathrm{p}$ value \\
\hline U D latency $(\mathrm{ms})$ & $3.03 \pm 0.62$ & $3.14 \pm 0.45$ & 0.673 \\
U CAMP $(\mu \mathrm{v})$ & $4.55(1.20-8.70)$ & $5.8(3.06-11.90)$ & 0.017 \\
U NCV $(\mathrm{m} / \mathrm{sec})$ & $58.29 \pm 6.88$ & $66.56 \pm 6.13$ & 0.0001 \\
U FW latency $(\mathrm{ms})$ & $29.35 \pm 5.47$ & $24.87 \pm 1.85$ & 0.016 \\
\hline
\end{tabular}

Results have been expressed as mean \pm SD and median (range) as appropriate.

Student's Unpaired ' $t$ '-test and Mann Whitney Ran Sum test were performed to calculated statistical difference between groups as applicable. P value $<0.05$ was taken as level of significance.

U D Latency, Ulnar distal latency; U CAMP, Ulnar Compound Muscle Action Potential; U NCV, Ulnar Nerve Conduction Velocity; U FW Latency, Ulnar F Wave Latency

\section{Table 4: Sensory nerve conduction parameters} of ulnar nerve

\begin{tabular}{l|c|c|c|}
\hline Variables & DM Subjects $(\mathrm{n}=32)$ & Control Subjects $(\mathrm{n}=30)$ & $\mathrm{p}$ value \\
\hline U D latency (msec) & $3.05 \pm 0.48$ & $3.09 \pm 0.28$ & 0.689 \\
U SNAP $(\mu \mathrm{v})$ & $10.9(4.2-23.6)$ & $11.05(8.2-19.4)$ & 0.683 \\
U NCV $(\mathrm{m} / \mathrm{sec})$ & $45.46 \pm 4.26$ & $46.41 \pm 7.73$ & 0.548 \\
\hline
\end{tabular}

Results have been expressed as mean $\pm \mathrm{SD}$ and median (range) as appropriate.

Student's Unpaired ' $t$ '-test and Mann Whitney Ran Sum test were performed to calculated statistical difference between groups where applicable. $\mathrm{P}$ value $<0.05$ was taken as level of significance.

U D latency, Ulnar distal latency; U SNAP, Ulnar 
Sensory Nerve Action Potential; U NCV, Ulnar Nerve Conduction Velocity.

Table 5: Motor nerve conduction parameters of peroneal nerve

\begin{tabular}{l|c|c|c}
\hline Variables & DM Subjects $(\mathrm{n}=32)$ & Control Subjects $(\mathrm{n}=30)$ & $\mathrm{p}$ value \\
\hline P D latency $(\mathrm{ms})$ & $4.35 \pm 2.68$ & $4.25 \pm 0.7$ & 0.829 \\
P CAMP $(\mu \mathrm{v})$ & $5.50(1.40-12)$ & $8.7(4.54-15.50)$ & 0.0001 \\
P NCV $(\mathrm{m} / \mathrm{sec})$ & $42.18 \pm 7.42$ & $53.72 \pm 6.49$ & 0.0001 \\
P FW latency $(\mathrm{ms})$ & $50.27 \pm 10.81$ & $41.32 \pm 3.05$ & 0.0001 \\
\hline
\end{tabular}

Results have been expressed as mean $\pm \mathrm{SD}$ and median (range) as appropriate.

Student's Unpaired ' $t$ '-test and Mann Whitney Ran Sum test were performed to calculated statistical difference between groups as applicable. P value $<0.05$ was taken as level of significance.

P D latency, Peroneal distal latency; P CAMP, Peroneal compound muscle Action potential; $\mathrm{P}$ NCV, Peroneal nerve conduction velocity; P FW Latency, Peroneal F wave latency.

Table 6: Sensory nerve conduction parameters of sural nerve

\begin{tabular}{l|c|c|c}
\hline Variables & DM Subjects $(\mathrm{n}=32)$ & Control Subjects $(\mathrm{n}=30)$ & $\mathrm{p}$ value \\
\hline S D latency $(\mathrm{ms})$ & $3.49 \pm 1.65$ & $3.40 \pm 0.48$ & 0.766 \\
S SNAP $(\mu \mathrm{v})$ & $12.30(0-28.8)$ & $14.05(8.02-46.4)$ & 0.075 \\
S NCV $(\mathrm{m} / \mathbf{s e c})$ & $35.22 \pm 14.40$ & $42.32 \pm 8.52$ & 0.019 \\
\hline
\end{tabular}

Results have been expressed as mean $\pm \mathrm{SD}$ and median (range) as appropriate.

Student's Unpaired 't'-test and Mann Whitney Ran Sum test were performed to calculated statistical difference between groups as applicable. $\mathrm{P}$ value $<0.05$ was taken as level of significance.

S D latency, Sural distal latency; S SNAP, Sural Sensory Nerve Action Potential; S NCV, Sural Nerve Conduction Velocity.

Table 7: Correlation analysis between fasting glucose and fructosamine with different nerve conduction variables of the diabetic subjects

\begin{tabular}{l|c|c}
\hline Variables & $\mathrm{r}$ & $\mathrm{p}$ \\
\hline Fasting glucose vs & & \\
MPNCV & -0.456 & 0.009 \\
Fructosamine vs & & \\
MPDL & 0.439 & 0.012 \\
MPNCV & -0.572 & 0.001 \\
MUNCV & -0.468 & 0.007 \\
SSNAP & -0.400 & 0.023 \\
USNAP & -0.409 & 0.020 \\
\hline
\end{tabular}

Pearson correlation analyses were performed. P value $<0.05$ was taken as level of significance.

MPNCV, Motor Peroneal nerve conduction velocity; MPDL, Motor Peroneal distal latency; MUNCV, Motor Ulnar nerve conduction velocity; SSNAP, Sural Sensory nerve action potential; USNAP, Ulnar Sensory nerve action potential.

Table 8: Endothelial dysfunction markers in the diabetic subjects with or without neuropathy and the controls

\begin{tabular}{l|c|c|c}
\hline Groups & ET-1 (pgm/ml) & t-PA $(\mathrm{ng} / \mathrm{ml})$ & vWF (iu/ml) \\
\hline DN $(\mathrm{n}=17)$ & $1.57 \pm 0.88$ & $18.79 \pm 12.18^{\mathrm{b}}$ & $1.73 \pm 0.50$ \\
DNN $(\mathrm{n}=15)$ & $1.69 \pm 1.09$ & $9.29 \pm 6.12^{\mathrm{a}}$ & $1.89 \pm 0.49$ \\
Control $(\mathrm{n}=30)$ & $1.24 \pm 0.45$ & $7.04 \pm 2.84^{\mathrm{a}}$ & $1.70 \pm 0.72$ \\
\hline
\end{tabular}

Results were expressed as Mean $( \pm S D)$.

Student's Unpaired ' $\mathrm{t}$ '-test was performed to calculated statistical difference between groups. $\mathrm{P}$ value $<0.05$ was taken as level of significance. Different superscript in the column indicated statistical significant difference.

t-PA, tissue Plasminogen Activator; ET-1, Endothelin-1; vWF, von Willibrand Factor.

DN, Diabetic neuropathy group; DNN, Diabetic nonneuropathy group

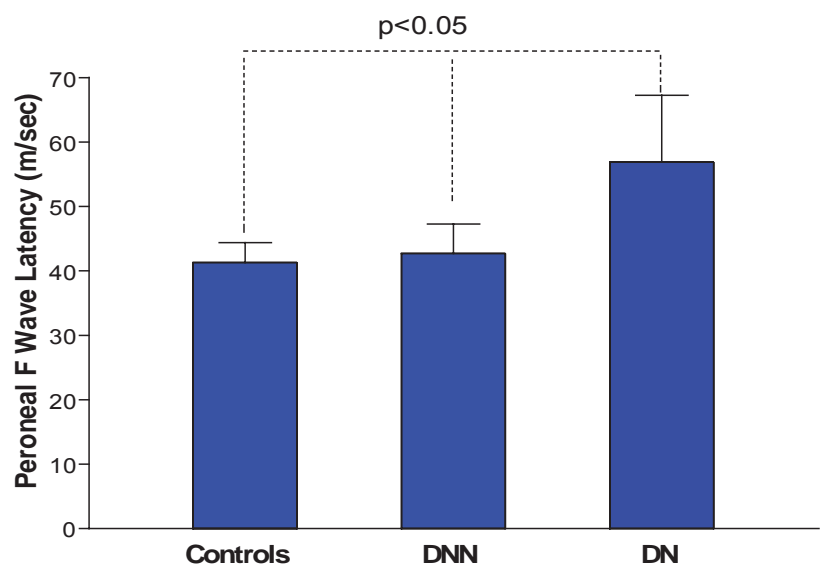

Figure 1: Peroneal F wave latency $(\mathrm{m} / \mathrm{sec})$ in the diabetic subjects with (DN) and without (DNN) neuropathy and the control subjects. 


\section{References:}

1. Vinik AI, Park TS, Stansberry KB, Pittenger GL. Diabetic neuropathies. Diabetologia. 2000; 43: 957-973. http://dx.doi.org/10.1007/s001250051477

2. Diabetes Control and Complications Trial Research Group. The effect of intensive treatment of diabetes on the development and progression of long-term complications in insulin-dependent diabetes mellitus. $N$ Engl J $\quad$ Med. 1993; 329: 977-86. http://dx.doi.org/10.1056/NEJM199309303291401

3. UK Prospective Diabetes Study Group. Intensive blood-glucose control with sulphonylureas or insulin compared with conventional treatment and risk of complications in patients with type 2 diabetes. Lancet. 1998; 352: 837-53 http://dx.doi.org/10.1016/S0140-6736(98)07019-6

4. Shaw JE, Zimmet PZ. The epidemiology of diabetic neuropathy. Diabetes Rev. 1999; 7: 245-52.

5. Duby JJ, Campbell RK, Setter SM, et al. Diabetic neuropathy: an intensive review. Am J Health-Syst Pharm 2004; 61: 160-176.

6 . The effect of intensive diabetes therapy on the development and progression of neuropathy. The Diabetes Control and Complications Trial Research Group. Ann Intern Med 1995;122:561-568 http://dx.doi.org/10.7326/0003-4819-122-8199504150-00001

7. Stratton IM, Holman RR, Boulton AJ. Risk factors for neuropathy in UKPDS (Abstract). Diabetologia 2004;47(Suppl. 1): A47

8. Dyck PJ, O'Brien PC, Litchy WJ, Harper CM, Klein CJ, Dyck PJ. Monotonicity of nerve tests in diabetes: subclinical nerve dysfunction precedes diagnosis of polyneuropathy. Diabetes Care 2005;28: 2192-2200 http://dx.doi.org/10.2337/diacare.28.9.2192

9. Poston L and Taylor PD. Endothelium-mediated vascular function in insulin dependent diabetes mellitus. Clinical Science, 1995; 88: 245-255.

10. Blan AD, Lip GYH, Endothelial Integrity, soluble adhesion molecules and platelet markers in Type 1 diabetes mellitus. Diabetic Medicine, 1998;15: 634-642. h t t p : / d x . d o i org / 10.1002 / ( S I C I ) 1096 9136(199808)15:8<634::AID-DIA636>3.0.CO;2-8

11. Takahashi K, Ghatei MA, Lam HC, Halloren DJO, Bloom SR. Elevated plasma endothelin in patients with diabetes mellitus. Diabetologia, 1990; 33: 306310. http://dx.doi.org/10.1007/BF00403325

12. Kessler L, Wiesel ML, Attali P, Mossard JM, Cazeneve JP, Pinget $\mathrm{M}$ et al. von Willebrand Faction in
Diabetic Angiopathy: Diabetes and metabolism 1998; 24: 327-336.

13. Plater ME, Ford I, Dent MT, Preston FE, Ward JD. Elevate von Willbrand factor antigen predicts deterioration in diabetic peripheral nerve function; Diabetologia, $\quad$ 1996, 39: 336-343. http://dx.doi.org/10.1007/BF00418350

14. Cagliero E, Roth T, Roy S, Lorenzi M. Characteristics and mechanisms of high glucose induced over expression of basement components in cultured human endothelial cells. Diabetes 1991; 40: 101-110. http://dx.doi.org/10.2337/diab.40.1.102

15. Mohajan S, Khan I, Mazumdar RM, Faruque MO, Hassan Z, Sikdar D, Ali L. Elevated Serum Endothelin-1 in Newly Diagnosed Type 2 Diabetes Mellitus is Associated with Hyperglycemia. Intern Med J (In press)

16. Celiker R, Basgoze O, Bayraktar M. Early detection of neurological involvement in diabetes mellitus. Electromyogr. Cli Neurophysiol. 1996; 36: 29-35.

17. Perkins BA, Olaleye D, Zinman B, Bril V. Simple screening tests for peripheral neuropathy in the diabetes clinic. Diabetes Care 2001;24(2):250-6. http://dx.doi.org/10.2337/diacare.24.2.250

18. Vinik AI, Kong X, Megerian JT, Gozani SN. Diabetic nerve conduction abnormalities in the primary care setting. Diabetes Technol Ther 2006; 8(6): 654-662. http://dx.doi.org/10.1089/dia.2006.8.654

19. Dyck PJ, Kratz KM, Karnes JL, Litchy WJ, Klein R, Pach JM, Wilson DM, O'Brien PC, Melton LJ 3rd, Service FJ. The prevalence by staged severity of various types of diabetic neuropathy, retinopathy, and nephropathy in a population-based cohort: the Rochester Diabetic Neuropathy Study. Neurology $\begin{array}{lllllllllllllll}1 & 9 & 9 & 3 & ; & 4 & 3 & : & 8 & 1 & 7 & - & 8 & 2 & 4\end{array}$ http://dx.doi.org/10.1212/WNL.43.4.817

20. Andesson H, Stalberg E, Flack B. F wave latency, the most sensitive nerve conduction parameter in patients with diabetes mellitus, Muscle and nerve 1997, Oct., 1297-1303.

21. Shaw JE, Sicree RA, Zimmet PZ.Global estimates of the prevalence of diabetes for 2010 and 2030. Diabetes Res Clin Pract 2010; 87(1): 4-14. http://dx.doi.org/10.1016/j.diabres.2009.10.007

22. World Health Organization (1999). Report of a WHO Consultation- Definition, Diagnosis and Classification of Diabetes Mellitus. Geneva: WHO; NCDS.

23. Bajaj JS. Malnutrition related ketosis-resistant diabetes mellitus- Classification, causes and mechanism. In: World book of diabetes in practice, Krall LP. (ed), 
Amsterdam, Elsevier, 1986: 276-280.

24. Hassan Z, Selim SI, Rahman M, Azad Khan AK, Rashid HU, Ali L, Saha S, Siddiq SK, Ahmed S, Nure-Alam $M$ and Haque MR. Microalbuminuria and early renal hemodynamic changes in diabetic subjects under 30 years of age. (Abstract). Diabetologia 1994; 37 (Suppl A).

25. Consensus Statement. Report and Recommendations of the San Antonio Conference on Diabetic Neuropathy Diabetes Care 1998; 11 (7): 592-597.

26. Fraser DM, Campbell IW, Ewing DJ, Murray A, Neilson JM, Clarke BF. Peripheral and autonomic nerve function in newly diagnosed diabetes mellitus, Diabetes, $\quad$ 1977; $\quad$ 26: 546-550. http://dx.doi.org/10.2337/diab.26.6.546

27. Graff RJ, Jeffery B, Heller E, Pote D. Nerve conduction abnormalities in untreated maturity-onset diabetes: Relation to levels of fasting plasma glucose and glycosylated haemoglobin. Ann Inter Med 1979; 90: 298-303. http://dx.doi.org/10.7326/0003-4819-90-3298

28. Kimura J, In: Electrodiagnosis in Diseases of nerve and muscle: Principle and practice. Edition 2, F.A. Davis Company, Philadelphia, 1989; 103-138.
29. Malik RA, Tesfaye S, Thompson SD, Vevas A, Sharma AK, Boulton AJM et al. Endothelial localization of microvascular damage in human diabetic neuropathy; Diabetologia, 1993, 36: 454-459. http://dx.doi.org/10.1007/BF00402283

30. Stehouwer CD, Lambert J, Donker AJ, van Hinsbergh VW. Endothelial dysfunction and pathogenesis of diabetic angiopathy. Cardiovasc Res. 1997;34(1):55-68. http://dx.doi.org/10.1016/S0008-6363(96)00272-6

31. Collier A, Rumely A, Rumley AG, Paterson JR, Learch JP, Lowe GDO. Free radical activity and haemostatic factors in NIDDM patients with and without microalbuminuria, Diabetes 1992; 41: 909-13. http://dx.doi.org/10.2337/diab.41.8.909

32. Porta M, Kohner EM, Molinatti GM, In-vivo studies of endothelial cell function in diabetic microangiopathy. In: Belfiore F, Mollinatti GM (eds), Frontiers in diabetes, vol. VIII. Vascular and Neurologic Complications of diabetes mellitus, Karger Basel, 1987, pp. 16-28.

33. Porta M, Maneschi F, White MC, Kohner EM. Twenty four hour variation of vWF and factor VIII related antigen in diabetic retinopathy. Metabolism 1981; 30: 695-699. http://dx.doi.org/10.1016/00260495(81)90085-8 